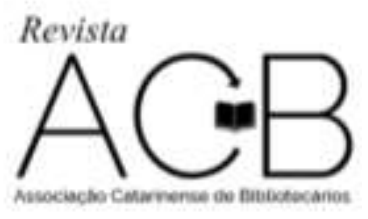

\title{
LETRAMENTO INFORMACIONAL POR MEIO DA PESQUISA ESCOLAR: RELATO DE UMA OFICINA COM O 5 ANO DO ENSINO FUNDAMENTAL
}

\section{Michelle Claudino Pires ${ }^{1}$ Uíliam Teixeira Terra ${ }^{2}$}

Resumo: Este artigo apresenta e avalia a realização de uma oficina de Pesquisa Escolar com estudantes do $5^{\circ}$ ano do Ensino Fundamental. O objetivo da atividade é o letramento informacional. Partindo de uma questão determinada pela professora, a oficina baseou-se em apresentação de fontes de informação e suas características; na seleção de fontes adequadas; oportunizou a prática da seleção das fontes, a sistematização da informação e a escrita do resultado da pesquisa, articulando e referenciando as informações selecionadas; por fim, a apresentação do trabalho. A oficina foi baseada em Kuhlthau (2004) e seu diferencial é o processo, com passos de pesquisa definidos.

Palavras-chave: Letramento Informacional. Pesquisa Escolar. Oficina de Pesquisa.

\section{INTRODUÇÃO}

Há uma distinção bastante significativa entre pesquisa de Iniciação Científica e Pesquisa Escolar. A primeira pressupõe a definição de uma questão, dos objetivos e de um método, que são propostos pelo pesquisador e são validados por uma comissão acadêmica. A pesquisa escolar, por sua vez, se dá por meio de fases ou passos, e baseia-se em proposta de investigação para o conhecimento de um tema ou de um fenômeno específico, que emergem dos conteúdos do currículo e das problematizações de sala de aula. Além da relevância da compreensão de um conteúdo proposto pelo professor, a pesquisa escolar pretende que os estudantes aprendam o processo de pesquisar: buscar informações e articular as ideias, a fim de gerar conhecimento.

Partindo do objetivo de promover a proficiência no processo de pesquisa, por meio dos recursos da biblioteca e de fontes virtuais, elaboramos, aplicamos e avaliamos uma oficina de pesquisa escolar. Ela partiu de uma proposta de pesquisa solicitada pela professora e consistiu na apresentação de todas as possibilidades de fontes de informação existentes no acervo da biblioteca do colégio e na pesquisa na Internet, que poderiam subsidiar a pesquisa proposta pela professora; na experiência de utilização e articulação das informações por parte

\footnotetext{
${ }^{1}$ Mestranda em Letras pelo Centro Universitário Ritter dos Reis (UNIRITTER). Especialista em Teoria e Prática da Formação do Leitor pela Universidade Estadual do Rio Grande do Sul (UERGS). Bacharela em Biblioteconomia pela Universidade Federal do Rio Grande do Sul (UFRGS). E-mail: pires.miche@hotmail.com

${ }^{2}$ Bacharel em Biblioteconomia pela Universidade Federal do Rio Grande do Sul (UFRGS). E-mail: uiliamterra@yahoo.com.br
} 
dos estudantes; até a apresentação da pesquisa em formato de trabalho acadêmico. A atividade foi realizada com estudantes das duas turmas de $5^{\circ}$ ano de um Colégio particular de Porto Alegre.

A oficina foi baseada em passos do processo de pesquisa bastante demarcados e fez uso de vários recursos informacionais e de variados espaços do Colégio: teve início em sala de aula, com a proposta de pesquisa e a apresentação das fontes de informação; passou pela pesquisa nas fontes na biblioteca, e em fontes virtuais nos computadores do laboratório de informática; em seguida passou pelo momento de leitura das fontes selecionadas na biblioteca, e terminou no laboratório de informática com formatação do trabalho para entrega (Word) e apresentação (Power Point).

Além da primordial necessidade do letramento informacional dos estudantes, o Projeto teve outra motivação: a preparação desses estudantes para o Projeto de Iniciação Científica do referido Colégio, que compreende as turmas do $6^{\circ}$ EF ao $3^{\circ}$ ano EM. Desta forma, a proposta da atividade teve também o objetivo de qualificar a pesquisa escolar, desde os Anos Iniciais, de forma que os estudantes cheguem à fase de processo de pesquisa científica já conseguindo buscar e selecionar fontes de informação e articulá-las para subsidiar a pesquisa.

Neste artigo, apresentaremos um breve referencial teórico sobre pesquisa escolar e fontes de informação; a metodologia aplicada na oficina; a experiência de aplicação, elencando os resultados positivos e os a melhorar, para a efetivação do objetivo de letramento informacional.

\section{PESQUISA ESCOLAR LETRAMENTO INFORMACIONAL E FONTES DE INFORMAÇÃO}

O processo de pesquisa consiste na sistematização de informações que são analisadas e compreendidas, gerando conhecimento sobre determinado tema ou assunto. Em âmbito escolar, na Educação Básica, um dos principais objetivos do processo de pesquisa é desenvolver a habilidade de pesquisar: "Para o estudante, aprender o processo de busca de informação é tão importante quanto expandir seu conhecimento sobre determinado assunto" (KUHLTHAU, 2010, p. 29). No processo de pesquisa "[...] deve ficar claro para o estudante que a pesquisa é um processo de busca de informação e que resulta na construção do conhecimento, apoiado nas experiências e vivências anteriores”. (REDE MARISTA..., 2013, p. 
[15]). Além disso, a pesquisa escolar colabora com o processo de ensino-aprendizagem no que respeita a compreensão e fixação de conteúdos ministrados em sala de aula. (CÔRTE, 2011, p.121).

Denominamos Letramento Informacional este processo que compreende a habilidade e a competência "[...] que permite integrar as ações de localizar, selecionar, acessar, organizar, usar informação e gerar conhecimento, objeto da aprendizagem, visando à tomada de decisão e resolução de problemas." (GASQUE; TESCAROLO, 2010, p. 41). Segundo os autores a relevância do letramento é fundamental para a formação de cidadãos atuantes frente aos desafios do nosso tempo, mas constatam que se percebe muita dificuldade de implementação na educação básica.

Para organizar a oficina, partimos dos pressupostos expressos por Kuhlthau (2004), de que: para que o processo de pesquisa ocorra de forma eficiente, desenvolvendo as habilidades/competência de pesquisa, é preciso que ocorra em passos bem definidos e organizados de forma que o estudante saiba o que ele já realizou e em que ponto irá chegar.

No que se refere à motivação, os estudantes devem ter a expectativa de que vão aprender algo novo e não somente vão atender à solicitação do professor. A respeito do contato com as fontes de informação, "Os alunos têm tendência a começar a tomar nota tão logo abrem o livro. Geralmente copiam palavra por palavra sem entender o significado do que estão escrevendo. É importante que entendam a diferença entre ter noção abrangente de um tópico e de dominar o detalhe." (KUHLTHAU, 2004, p. 186) O processo de pesquisa gera sentimentos que vão de confusão à ansiedade, mas é preciso que os estudantes tenham a perspectiva que até o final do processo o sentimento será de satisfação pela compreensão do assunto e pela autoria desta construção.

É senso comum que em pesquisa não é preciso "inventar a roda". Muito já foi estudado e produzido e a ciência se baseia nesses dados para embasar e superar o conhecimento. $O$ suporte onde as informações estão registradas denomina-se Fonte de Informação. Considerase "[...] fontes de Informação os materiais ou produtos, originais ou elaborados, que contenham notícias ou testemunhos, através dos quais se acessa ao conhecimento, qualquer que seja este." (SAINERO; SÁNCHEZ; QUINTANA SÁENZ, 1994, p. 30). Elas são classificadas de diversas maneiras por sua origem e natureza.

Possuir diversas fontes de informação é essencial para a biblioteca ser um centro de mediação entre a informação e o usuário. Contudo, deve-se prezar pela qualidade da fonte e 
pensar na relevância que ela tem para seu público, a fim de efetivar seu uso na biblioteca ou em sala de aula. Para isso é importante definir e conhecer o que são fontes de informação para mais tarde pensar quais são importantes para a sua instituição.

$\mathrm{Na}$ biblioteca escolar podemos encontrar informação em diversas fontes como: livros, revistas, jornais, mapas e na internet com o uso das tecnologias.

A pesquisa escolar requer a utilização das fontes para responder uma questão ou necessidade de informação, para isso é importante que o estudante saiba procurar ou precise de orientação para a fonte adequada a sua pesquisa, neste sentido é preciso saber o que cada fonte possui de informação. Em uma pesquisa pode se utilizar vários recursos a fim de conhecer o tema para melhor responder a pesquisa.

Apresentam-se os tipos de fontes de informação disponíveis no Colégio e sua definição:

Livros: Livro é um documento formado pela reunião de folhas ou cadernos, constituindo uma unidade bibliográfica, normalmente serve para oferecer ao leitor um conjunto de conhecimento consolidados sobre uma especialidade ou estudo aprofundado de um tema restrito. Tipos de livros: de literatura, especializados, didáticos, entre outros.

Dicionários: O dicionário é uma obra de referência que dá informação sobre as palavras e sua grafia, pronúncia, significado, etimologia, sinonímia e antonímia. Define termos de forma simplificada e, às vezes, dá breves indicações sobre as aplicações dos conceitos que expressam.

Enciclopédias: é uma obra em vários volumes, que traz informações sobre todos ou sobre alguns ramos do conhecimento, em geral, apresenta-se na forma de verbetes ordenados em ordem alfabética ou sistemática.

Periódicos: publicação seriada de periodicidade prefixada, cujas unidades são geralmente constituídas por textos de autoria diversa.

Revistas: tem o papel informativo, contendo artigos especializados, científicos ou de entretenimento.

Jornais: desempenham um papel informativo, assim como a revista, oferecendo ao leitor um leque selecionado de notícias e artigos a partir dos principais acontecimentos de uma cidade, estado, país ou parte do mundo. 
Mapas e globos: representam elementos da superfície terrestre, no todo ou em parte, por meio de linhas, escalas, cores e símbolos convencionais, dependendo de seus objetivos, os mapas podem ser classificados como: políticos, físicos, marítimos e temáticos.

Internet: A internet é um sistema de informação que tem por suporte uma rede global, que consiste em centenas de milhões de computadores conectados entre si, ao redor do mundo. Neste sentido é um meio eletrônico digital e que é capaz de incorporar todas as outras fontes, além de fornecer outras fontes como sites, blogs e base de dados.

A fim de justificar a proposta de trabalho que exigiu o envolvimento da Coordenação Pedagógica, das Professoras e da Equipe da Biblioteca, nos baseamos nas orientações de um Projeto Educativo do referido Colégio, elaborado no ano de 2010, que, a respeito das definições dos espaços tempos de investigação e produção do conhecimento nos dá a diretriz. Trata da necessidade de

[...] construção de itinerários pessoais e/ou coletivos, para a construção crítica de novos saberes, discursos, conhecimentos, habilidades, linguagens e tecnologias. [...] as aulas cujos pressupostos são a pergunta, a busca de informações, conhecimentos, conceitos e significados em materiais/fontes/espaços diversificados; o uso de múltiplas linguagens; a utilização de espaços diversificados para a aprendizagem; a reflexão e tomada de decisão, entre outras, que resultam numa produção de conhecimentos mais abrangente e complexa. (UNIÃO MARISTA DO BRASIL, 2010, p.68)

Então, aprender a utilizar os recursos bibliográficos existentes na biblioteca, bem como os recursos tecnológicos para busca por informação, fazendo com que a formação aconteça nos espaços mais variados, como na sala de aula, no laboratório informática e na biblioteca, estão completamente de acordo com as diretrizes da Rede e cumprem com os seus objetivos educativos. 


\section{DESCRIÇÃO DA OFICINA}

O processo de pesquisa completo ocorreu em cinco aulas, entre os meses de outubro e novembro de 2015. A definição do tempo do processo foi determinada pelas professoras, dentro das possibilidades do calendário escolar e da sistematização do currículo. Foi levado em consideração que, entre a leitura e a síntese das informações para escrever os resultados da pesquisa, era necessário um tempo de maturação das ideias.

Em todos os passos do processo a equipe da Biblioteca esteve envolvida, trabalhando em parceria com as duas professoras das turmas de $5^{\circ}$ ano e com a equipe da Tecnologia Educacional do Colégio, sob o aval e acompanhamento da Coordenadora Pedagógica.

Como recursos para a oficina foram utilizados: livros de Referência (dicionários especializados, enciclopédias; guias etc.); Livros informativos (paradidáticos); Periódicos; DVDs. Todas as possibilidades de localização de informação nestes documentos foram escaneadas para que toda a turma pudesse acompanhar a busca no sumário, no índice, em verbetes e a o resultado da informação encontrada. Para isso, foi utilizado o projetor da sala de aula; o espaço da biblioteca, suas mesas, foram utilizados para a pesquisa e leitura dos documentos; o laboratório de informática com acesso à internet foi utilizado para a pesquisa e o recurso do Word para digitação e formatação do trabalho.

Nas próximas subseções apresenta-se o esquema da oficina proposta, organizada em oito passos que sistematizaram o processo de pesquisa (ver em 3.1), tendo início com a proposta de tema dado pela professora até a apresentação do resultado da pesquisa à comunidade escolar. Esses passos foram distribuídos em cinco aulas, cuja descrição foi apresentada na subseção 3.2.

\subsection{PASSOS DA PESQUISA}

Apresenta-se o esquema da oficina com a proposta dos oito passos que sistematizam o processo de pesquisa, baseado e adaptado do modelo de Kuhlthau (2004).

PASSO 1: Proposição aos estudantes do assunto a ser pesquisado

Foi apresentada pela professora a proposta da pesquisa - a biografia de Getúlio Vargas deixando claro o que se pretendia com a pesquisa, qual o objetivo e onde se quer chegar. Por 
meio de questionamento, foi-se identificando os conhecimentos prévios dos estudantes sobre o biografado, a fim de partir dos conhecimentos deles para pensar a busca por informação. Os estudantes foram organizados em grupos para a realização da pesquisa.

PASSO 2: Situar o aluno nos estágios da pesquisa

Ao longo do processo fomos retomando e apontando em que fase do processo de pesquisa eles estão e o que faltava ainda realizar para chegar no objetivo. Isso ajudou a compreender o processo e minimiza a ansiedade dos estudantes. Kuhlthau (2010) dá uma sugestão de linha do tempo que adaptamos aqui:

LINHA DO TEMPO DO PROCESSO DE PESQUISA
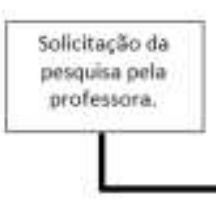

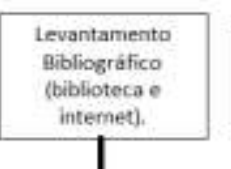

internet).
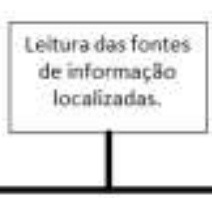

Seleçāo das fontes que seräo utilizadas na pescuisa e registro na Ficha de Leitura.



Fonte: Do Autor. (2015). Adaptado de Kuhlthau (2004)

PASSO 3: Levantamento de dados por parte dos estudantes

Os estudantes foram encaminhados à biblioteca e à informática para identificarem as possíveis fontes de informação que poderiam ajudá-los a resolver a questão proposta. Este é o passo em que a equipe da biblioteca pode dar o maior apoio à pesquisa: mostrando para os estudantes como localizar informação no catálogo da biblioteca, no acervo e a buscar fontes na internet. Foi preciso organizar estratégias em conjunto com a professora para que estas orientações se efetivassem.

Habilidades/competências que tínhamos o objetivo de desenvolver: diferenciar os tipos de fontes de informação; identificar como o conhecimento está organizado no acervo da biblioteca; compreender a organização da informação em um documento: sumário, índice etc.; aprender a selecionar termos e estratégias de busca em catálogos da biblioteca e na internet; pré-seleção de fontes que podem ser relevantes para a pesquisa. 
PASSO 4: Leitura individual das fontes de informação pré-selecionadas.

Proporcionamos espaço/momento para esta leitura. Orientamos a sistematização das informações mais importantes segundo o objetivo da pesquisa, encontrada em cada fonte de informação. Entregamos um formulário para preenchimento dos dados bibliográficos da obra e das ideias principais, em modelo semelhante à ficha de leitura.

Habilidades/competências a serem desenvolvidas neste passo: ler o documento apreciando seu contexto geral sem se prender a cada detalhe escrito; sintetizar e redigir a ideia geral do autor e focar no detalhe do conteúdo somente se for relevante para a pesquisa; anotar as informações sobre a fonte de informação: título, autor e data: observar autoria e se é uma informação atual ou antiga; compreender a ideia de plágio: não se usa a escrita/conhecimento de outra pessoa sem indicar de quem é; selecionar fontes de informação adequadas à sua pesquisa.

PASSO 5: Reflexão sobre o que foi lido.

Leitura das anotações feitas nas fichas e refletir: aprendi algo novo? Já tenho informação suficiente para responder à pergunta de pesquisa? Se não tiver, o estudante deve ser orientado a voltar ao PASSO 3 e identificar outras fontes de informação.

Habilidades /competência a ser desenvolvida: reconhecer a capacidade compreender sobre um assunto através da leitura de várias fontes; articular informações; reconhecer quando os dados levantados não foram suficientes ou adequados; perceber seu potencial reflexivo e sua capacidade de gerar informação e agregar novo conhecimento.

PASSO 6: Sistematização das informações e escrita do texto.

Organização do resultado da pesquisa e resposta da questão inicial:

a) Introdução: apresentação do tema/questão que gerou a pesquisa; um pequeno resumo sobre o tema; objetivos com a pesquisa que será apresentada.

b) Desenvolvimento: apresentação das informações encontradas nas fontes de pesquisa; relação e discussão das informações encontradas; reflexão gerada sobre o tema/conteúdo a partir das informações; resposta à questão de pesquisa refletida pelo estudante que não precisa estar fechada.

c) Considerações Finais: apresentação dos resultados da pesquisa e espaço para realizar novas indagações a partir dos resultados, caso ocorra esta possibilidade. 
d) Referências: lista de obras que foram utilizadas para a pesquisa.

PASSO 7: Formatação do trabalho escrito para entrega (Word) e organização da apresentação da pesquisa à turma em formato de slides (Power Point)

PASSO 8: Apresentação do trabalho à comunidade escolar (turma).

\subsection{ROTEIRO DAS AULAS}

A seguir, apresenta-se o roteiro das cinco aulas realizadas com as turmas dos $5^{\circ}$ anos, que compreendem os oito passos da pesquisa relatados na seção 3.1 .

\subsubsection{AULA 1 - APRESENTAÇÃO DA PROPOSTA DE TRABALHO E DE FONTES DE INFORMAÇÃO}

Os Bibliotecários apresentaram diversas fontes de informações já pré-selecionadas, em que haviam informações sobre Getúlio Vargas, para a turma identificar se seriam boas fontes para o objetivo da pesquisa ou não. Por meio da explanação e manuseio dos recursos, pretendíamos que os estudantes conhecessem os vários tipos de fontes de informação e o tipo de informação encontrada nelas e quais os recursos de busca (sumário, índice, capítulos, verbetes etc.)

A seguir, apresenta-se o roteiro da aula/oficina:

a) Retomamos os conhecimentos prévios dos estudantes sobre a Era Getúlio Vargas;

b) Apontamos que a Era Vargas aconteceu em função de um homem: Getúlio Vargas. Então a professora lançou a proposta de pesquisa: como foi a vida do homem Getúlio Vargas, onde nasceu, quando, se se casou, onde e o que estudou, viveu em que cidade, viajou, teve filhos, qual a sua música ou comida preferida, tinha alguma mania, qual a sua profissão, quando faleceu etc. Então, a pesquisa proposta foi a respeito de dados biográficos deste personagem da história.

c) Apresentamos a linha do tempo do processo de pesquisa, com os 8 passos a serem percorridos; 
d) Consideramos que quando se quer saber sobre a vida de alguém, precisamos iniciar uma busca de informações, que pode ser na Internet ou em documentos impressos organizados no acervo de uma biblioteca. O foco desta aula são os materiais existentes na Biblioteca. Começamos com livros de Referência.

e) Chamamos um voluntário para avaliar se em um dicionário de língua portuguesa é possível encontrarmos informações sobre Getúlio Vargas. O dicionário foi manipulado pelo estudante que concluiu que não há informações ali.

f) Chamamos um 2o voluntário. Apresentamos uma enciclopédia, a Delta Universal 3 . Comparamos-na com a Wikipedia. Questionamos se sabiam como ela é organizada. Que tipo de informação contém? Então explicamos a sua estrutura e seu conteúdo. $O$ voluntário foi convidado a fazer a busca: por que termo buscaria? Getúlio Vargas? Não localizou. E pelo termo Vargas, Getúlio? Por meio de slides, projetamos a imagens escaneadas da página da enciclopédia, mostrando que uma expressão de busca contém vários subcapítulos temáticos. Questionamos quais subcapítulos podem conter informações sobre a vida de Getúlio Vargas.

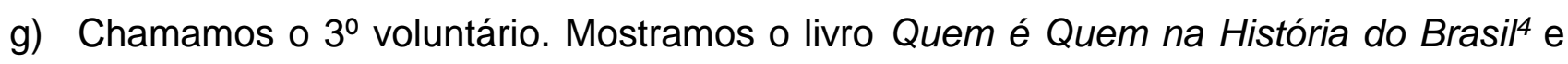
explicamos sobre este tipo de fonte de informação, seu conteúdo e sua organização. Questionamos se neste livro seria possível conter informações sobre Vargas. Mostramos no slide a informação localizada e começar a ler com o grupo: contém dados biográficos?

h) Chamamos o $4^{0}$ voluntário. Mostramos o livro Os 1000 que fizeram o século $20^{5}$. Vargas foi alguém importante na história do Brasil? Vargas viveu e atuou durante o século 20? É possível encontrarmos informações sobre Vargas neste livro? Pedimos que o voluntário fizesse a busca, não no sumário, pois não havia, mas pelos verbetes.

i) Chamamos um 5o voluntário. Apresentamos o Almanaque Abril6. Mostramos que ele traz dados atuais e históricos. Apresentamos o sumário. Seria possível encontrar a informação por esse recurso? Identificamos que pelo sumário é possível localizar grandes temas e que eles têm seus próprios sumários, com os assuntos mais

\footnotetext{
${ }^{3}$ ENCICLOPÉDIA Delta Universal. Rio de Janeiro: Delta, 1991. 15 v.

${ }^{4}$ QUEM é quem na história do Brasil. São Paulo: Abril, 2000.

51000 QUE fizeram o século 20. São Paulo: Três, [199-]. 329 p.

${ }^{6}$ ALMANAQUE Abril 2014. 40. ed. São Paulo: Abril, 2014. 730 p.
} 
específicos. Mostramos que por meio do índice, podemos chegar bem facilmente às páginas que trazem informação sobre a personagem pesquisada: Vargas, Getúlio.

j) Questionamos se perceberam alguma característica nestes livros que olhamos, a fim de esclarecermos que todos estão organizados por verbetes. Que não são organizados para serem lidos do início até o final, como um romance ou uma biografia. São livros para consulta. São organizados dentro da biblioteca onde chamamos de "Coleção de Referência”. Por isso não são emprestados, servem para tirar dúvidas, iniciar uma pesquisa. Mostramos a foto de onde fica esta coleção na Biblioteca do CMA.

k) Passamos a mostramos os livros que pertencem ao acervo geral:

- Romance ${ }^{7}$. Perguntamos se em um romance, mesmo que seja histórico, se podemos usar dados para pesquisa.

- Biografia. ${ }^{8}$ Falamos sobre o que é uma biografia. Podemos encontrar dados biográficos sobre Getúlio Vargas nesta biografia? Sim. Mas, como é uma obra bastante extensa e não temos muito tempo podemos usar uma parte específica deste livro: as fotos. Há descrição nelas que podemos utilizar como fonte de informação.

- Paradidático de história De Getúlio a Getúlio9. Refletimos: verificando o sumário, percebemos se há chance de ter dados biográficos? Chamamos o $7^{\circ}$ voluntário para pesquisar. Concluímos que é preciso explorar os materiais/livros para conhecer seu potencial de informação. Às vezes o sumário não diz tudo.

- Chamamos o 6o voluntário. Apresentamos um livro didático de História e Geografia do $4^{0}$ ano $^{10}$. Se Getúlio Vargas foi uma pessoa relevante para a história do Rio Grande do Sul e do Brasil, poderia estar citado em livros de História? Será que neste tipo de livro há dados biográficos? Em que período político Getúlio Vargas comandou o Brasil (Período Colonial, Imperial ou Republicano?). Pedimos que o voluntário analisasse o sumário. Apresentar 0 sumário para a turma no slide.

\footnotetext{
${ }^{7}$ JAF, Ivan. O vampiro que descobriu o Brasil. 5. ed. São Paulo: Ática, 2002. e FONSECA, Rubem. Agosto. São Paulo: Companhia das Letras, 2006.

${ }^{8}$ LIRA NETO. Getúlio: do governo provisório à ditadura do estado novo (1930-1945). São Paulo: Companhia das Letras, 2013.

${ }^{9}$ DORATIOTO, Franscisco F. M.; DANTAS FIHO, José. De Getúlio a Getúlio: o Brasil de Dutra e Vargas - 1945-1954. 12. ed. São Paulo: Atual, 1991. 90 p.

${ }^{10}$ SCHNEIDER, Regina Portella. Rio Grande do Sul: história e geografia. São Paulo: FTD, 2011.
} 
l) Chamamos o $8^{\circ}$ voluntário. Passamos então aos materiais especiais (periódicos e multimídia). Mostramos a revista Aventuras na História11. Questionamos se numa revista deste tipo pode haver dados sobre Getúlio Vargas. Questionamos se nas revistas Placar ou Caras poderíamos encontrar informação sobre Getúlio. Refletimos que nas revistas encontramos as informações mais novas descobertas, já que são de rápida circulação (um livro demora a ser editado). Pedimos ao que voluntário analisasse a capa. A matéria que se destaca pode falar de Vargas? Sumário. Lermos juntos a reportagem. Há dados biográficos?

m) Mostramos o DVD. ${ }^{12}$ Trata de um documentário e não de um filme de ficção. Um documentário pode ser uma boa fonte de informação? Neste documentário podem constar dados biográficos? De que período se trata? (1930-1935). Há chance de falar sobre a vida de Vargas?

Para finalizar a aula do dia, retomamos a linha dos passos da pesquisa e conversamos sobre a fase de pesquisa que estamos: seleção de fontes de informação. O próximo passo é a leitura e a coleta de informações que vão dar conta da pesquisa. Ocorrerá na Biblioteca no dia x. Todos estes livros estarão à disposição e eles poderão buscar outras fontes por lá.

\subsection{AULA 2 - LEITURA NA BIBLIOTECA E PREENCHIMENTO DA FICHA DE LEITURA}

Organizados nas mesas da biblioteca, cada dupla leu de forma integral o texto ou o capítulo de uma das fontes selecionadas na aula anterior. Ao término da leitura, antes de trocarem as fontes entre os colegas, questionamos se as informações constantes nas fontes lidas eram úteis para a pesquisa. Se positivo, a dupla recebeu um formulário, uma Ficha de Leitura em que foram orientados a registrar os dados da obra e as informações importantes encontradas.

\footnotetext{
${ }^{11}$ AVENTURAS NA HISTÓRIA: para viajar no tempo. São Paulo, n.129. abr. 2014. ISSN 1806-2415.

${ }^{12}$ ESCOREL, Eduardo. Era Vargas. Log On DVD. 196 min.
} 


\subsubsection{AULA 3 - PESQUISA NA INTERNET E PREENCHIMENTO DA FICHA REGISTRO DE LEITURA}

No Laboratório de Informática, a funcionária da Tecnologia Educacional guiou a atividade. A equipe da Biblioteca ficou à disposição para orientação aos estudantes. Os bibliotecários elencaram algumas dicas para avaliação de fontes de informação na internet:

a) Verificar a autoria das fontes de informação na Internet;

b) A Wikipédia está se aprimorando, há mecanismos para correção da informação e indicação de bibliografia, mas solicitamos que não utilizassem como fonte de pesquisa, que explorassem outras possibilidades na Internet.

c) Verificar atualização das informações (data do documento, data de atualização da página etc.);

d) Usar como fonte de informação: homepages de instituições que tenham compromisso com a pesquisa; periódicos online; a homepage de um pesquisador ou de um professor. Lembramos que qualquer fonte de informação pode oferecer informações parciais, por isso sempre é bom pesquisarmos em mais de uma.

e) Verificar se há bibliografia indicada;

\subsubsection{AULA 4 - REDAÇÃO DO TRABALHO E FORMATAÇÃO}

Apresentamos aos estudantes a estrutura de um trabalho acadêmico, com o recurso do Word, contendo Introdução, desenvolvimento e conclusão ou discussões e as referências. Para cada capítulo explanamos a forma de estruturá-los, que tipo de informação deve apresentar e exemplos.

\subsubsection{AULA 5 - POWER POINT}

No laboratório de Informática, com a profissional da Tecnologia Educacional, foram orientados em como montar apresentação de trabalhos em slides do PowerPoint: apresentação, informações mais relevantes da pesquisa, referência e agradecimento. 


\section{DISCUSSÃO E AVALIAÇÃO DA ATIVIDADE}

Após a realização da atividade, a equipe da Biblioteca refletiu e fez apontamentos, por meio de livre observação, dos pontos positivos da oficina e dos pontos a serem revistos a readequados para que o objetivo do projeto seja alcançado.

Foram observadas as seguintes fragilidades do modelo proposto:

É necessário que os passos do processo de pesquisa, bem como a forma de dinamizálos seja dominado por todos os educadores envolvidos no projeto: as professoras, a equipe da Biblioteca (bibliotecários e auxiliares), o profissional da Tecnologia Educacional, para que, cada um faça sua contribuição para a formação do estudante. Percebemos que a falta de compreensão do processo como um todo por parte dos educadores pode ter atrapalhado um pouco a percepção do estudante sobre o próprio processo de pesquisa deles.

O acervo da biblioteca precisa estar atualizado, contendo fontes de informação muito variadas, e em quantidade suficiente para que as turmas possam efetivar a pesquisa, e, consequentemente, valorizar o setor como um apoio às suas necessidades de informação.

Como uma primeira experiência, observamos que é muito forte a tendência da cópia por parte dos estudantes. Com o trabalho foi feito em duplas, um lia e o outro copiava a informação na ficha de leitura, - embora já tenha aprendido a fazê-lo entre aspas (citação direta). Esta prática de cópia precisa de orientação contínua para que deixe de ocorrer. É uma cultura a ser mudada. $O$ tempo dado a leitura também precisa ser valorizado e ampliado, de forma que os estudantes completem a atividade.

Como sucesso da atividade apontamos a parceria entre educadores e setores para um objetivo comum, com potencial para qualificar o processo de pesquisa, o ensino e a aprendizagem. Apontamos a oportunidade de os estudantes conhecerem e manusearem variados tipos de fontes de informação, tanto impressa quanto virtuais e a possibilidade de terem sido orientados presencialmente para seleção e uso. Destacamos também o fato de os estudantes terem praticado e percebido que não é necessário copiar toas as informações de um documento, mas selecionar a informação central ou as mais relevantes, e parafrasear, extraindo o que mais interessa para a pesquisa. Tiveram uma noção de plágio e que a cópia precisa ser referenciada. 
Com o uso em larga escala da internet, observa-se a tendência em resolver todas as questões de pesquisa por meio de buscadores, como o Google. Essa tendência acaba por deixar a Biblioteca à margem dos processos de pesquisa escolar, tanto do ponto de vista do estudante quanto do próprio educador. A oficina deu oportunidade, então, para a Biblioteca ser recolocada no processo de aprendizagem e de pesquisa como um setor de apoio.

A atividade deixou a expectativa da sistematização das pesquisas escolares neste formato, possível de aplicação em todos os conteúdos curriculares e com todos os níveis de ensino, adaptado às realidades do desenvolvimento dos estudantes.

\section{CONSIDERAÇÕES FINAIS}

Neste artigo fizemos um relato de uma experiência de oficina de letramento informacional, realizada com estudantes dos $5^{\circ}$ anos. A oficina teve foco no conhecimento, seleção e uso da informação, para a pesquisa escolar. Demos ênfase à importância de conhecer os mais diversos suportes de informação e orientamos a seleção das fontes por sua relevância para os objetivos da pesquisa; destacamos a necessidade de organizar as informações em fichas de leitura para depois articular as informações encontradas em um texto, que revela os conhecimentos advindos da pesquisa e que referencia as fontes de pesquisa. $O$ artigo salientou também a relevância do trabalho integrado entre professores e setores escolares, no caso, a Biblioteca e a Tecnologias Educacionais, no objetivo de formação dos estudantes para a pesquisa.

A proposta da oficina, em que os materiais impressos existentes na biblioteca são explorados, deu oportunidade para a Biblioteca retomar a sua relevância no processo de ensino-aprendizagem, em uma realidade em que as soluções de pesquisa são, parcialmente, encontradas na internet, muitas vezes sem a mediação de um educador ou de um profissional da informação.

Sendo uma atividade ocorrida em uma única edição, baseada em teoria (Kuhlthau, 2004) apresentamos algumas fragilidades encontradas no processo de pesquisa, das quais apontamos: o conhecimento de todo o processo da pesquisas, seus tempos e passos, por parte equipe de educadores, para auxiliar os estudantes; a cultura de pesquisa dos estudantes baseada na cópia; o tempo que é possível destinar à leitura e à maturação das 
ideias para a produção de conhecimento - a relação delicada entre o tempo disponível no currículo e o tempo necessário.

O reconhecimento e a busca por soluções dos pontos fracos da experiência de pesquisa é necessária para que as suas potencialidades efetivem o objetivo do Projeto, que é o letramento informacional e a proficiência no uso da informação. Dentre os sucessos da atividade elencamos a fundamental parceria entre educadores e setores para um objetivo comum, com o potencial de casa um para qualificar o processo de pesquisa, o ensino e a aprendizagem; a oportunidade dos estudantes conhecerem as mais diversas fontes de informação, as estratégias de busca, bem como o uso adequado às normas acadêmicas e a apresentação dos resultados.

A continuidade do projeto, aplicado em vários níveis da educação básica, aplicado para todas as áreas do conhecimento, tendem a qualificar o próprio e atingir o objetivo educacional voltado para a pesquisa.

\section{REFERÊNCIAS}

CAMPELLO, Bernadete Santos; CALDEIRA, Paulo da Terra. Introdução às fontes de informação. 2. ed. Belo Horizonte, MG: Autêntica, 2008.

CARRIZO SAINERO, Gloria. Las fuentes de la información. In: CARRIZO SAINERO, Gloria; SÁNCHEZ, Pillar Irureta-Goyena; QUINTANA SÁENZ, Eugenio Lópes de. Manual de Fuentes de Información. Madrid: Confederación Española de Gremios y Asociaciones de Libreros, 1994. Cap. 1, p. 17-44.

CÔRTE, Adelaide Ramos e; BANDEIRA, Suelena Pinto. Biblioteca escolar. Brasília: Briquet de Lemos, 2011.

CUNHA, Murilo Bastos da. Manual de fontes de informação. Brasília, DF: Briquet de Lemos, 2010.

KUHLTHAU, Carol. Como orientar pesquisa escolar: estratégias para o processo de aprendizagem. São Paulo: Autêntica, 2010.

GASQUE, Kelley Cristine Gonçalves Dias; TESCAROLO, Ricardo. Desafios para implementar o letramento informacional na educação básica. Educação em Revista, Belo Horizonte, v.26, n.01, p.41-56, abr./2010. Disponível em: <http://www.scielo.br/pdf/edur/v26n1/03.pdf>

KUHLTHAU, Carol. Como usar a biblioteca na escola: um programa de atividades para o ensino fundamental. São Paulo: Autêntica, 2004. 
REDE MARISTA DE CLÉGIOS DO RIO GRANDE DI SUL E BRASÍLIA. Diretrizes para projeto de pesquisa científica. Porto Alegre: Centro Marista de Comunicação, 2013 (no prelo).

UNIÃO MARISTA DO BRASIL. Projeto Educativo do Brasil Marista. Brasília: UMBRASIL, 2010.

\title{
AGRADECIMENTOS
}

Agradecemos, primeiramente ao Colégio, pela confiança e apoio nos Projetos que a Biblioteca propõe. Agradecemos a toda a equipe de educadores envolvida no projeto: começando pela Coordenação Pedagógica que reconheceu a relevância da proposta e articulou com as professoras a ocorrência da atividade. Às professoras dos $5^{\circ}$ anos que acolheram a proposta e dedicaram-se para que ele ocorresse como o planejado; à equipe da TE que tomou para si a responsabilidade de dinamizar e orientar as pesquisas na Internet e a formatação dos trabalhos. À equipe da Biblioteca que reconhece a sua missão de mediar a relação entre o usuário e a informação, e que auxiliou muito no processo dos estudantes de leitura e escrita. E, finalmente, aos estudantes, que são a nossa fonte de inspiração e o motivo para quem trabalhamos.

\section{INFORMAL LETTERS THROUGH SCHOOL RESEARCH: REPORT OF AN OFFICE WITH THE FIVE YEARS OF FUNDAMENTAL EDUCATION}

\begin{abstract}
This article presents and evaluates the realization of a School Research workshop with students of the 5th year of Elementary School. Her goal is informational literacy. Based on a question determined by the teacher, the workshop was based on the presentation of information sources and their characteristics; Selection of appropriate sources; Facilitated the practice of selecting sources, systematizing information and writing the research results, articulating and referencing the information selected; Finally, the presentation of the work. The workshop was based on Kuhlthau (2004) and its differential is the process, with defined research steps.
\end{abstract}

Keywords: Informational Literature. School research. Research Office.

RECEBIDO: 24-03-2018

ACEITO: 05-05-2017 